\title{
Microstructuring glass surfaces using a combined masking and microslurry-jet machining process
}

\author{
Yoshitaka Nakanishi $^{\text {a, }}$, Yuta Nakashima ${ }^{\text {a,b }}$, Emile van der Heide ${ }^{\text {c,d }}$ \\ ${ }^{\text {a }}$ Faculty of Advanced Science and Technology, Kumamoto University, 2-39-1 Kurokami, Chuo-ku, Kumamoto, 860-8555, Japan \\ ${ }^{\mathrm{b}}$ International Research Organization for Advanced Science \& Technology, Kumamoto University, 2-39-1 Kurokami, Chuo-ku, Kumamoto, 860-8555, Japan \\ ${ }^{\mathrm{c}}$ Faculty of Engineering Technology, University of Twente, Drienerolaan 5, 7522, NB, Enschede, the Netherlands \\ ${ }^{\mathrm{d}}$ Faculty of Engineering and Architecture, Ghent University, Graaf Karel de Goedelaan 5, B-8500, Kortrijk, Belgium
}

\section{A R T I C L E I N F O}

\section{Keywords:}

Micromachining

Microslurry-jet

Photolithography

Glass

Mechanical removal process

\begin{abstract}
A B S T R A C T
The combined application of a conventional photoresist masking process and microslurry-jet (MSJ) mechanical removal process was studied for microstructuring the surface of glass. Masking patterns made of a photocurable resin (SU-8) were created on the glass, and both the SU-8 patterns and exposed glass surface were simultaneously removed using the MSJ. When the sacrificial patterns of the SU-8 were removed by the MSJ, the glass surface with microstructures was created. Post-treatment, such as removal of the SU-8 patterns, was not required. Confocal microscopy results confirmed that continuously curved convex structures up to $30 \mu \mathrm{m}$ in diameter and $4 \mu \mathrm{m}$ in height with highly transparent glass surfaces were created. The microstructures reduced the hydrophilicity of the glass surfaces. Future studies on identifying materials compatible with glass for making masking patterns and showing good wear resistance might prove the feasibility of this method in producing structured engineering surfaces.
\end{abstract}

\section{Introduction}

A variety of manufacturing processes have been developed and evaluated for structuring engineering surfaces at the microscale. Applications range from modifying tribological properties, for which the relationship between friction and surface textures is researched $[1,2]$, to inducing hydrophobicity by microstructuring surfaces [3], where contact angle measurements are used to assess the hydrophobicity or hydrophilicity of the surfaces. Convex microstructural features might offer additional advantages in this context [4]. The manufacturing processes for engineering surfaces can involve techniques such as spraying, where material is added to surfaces for generating random or hierarchical roughness [5]; these manufacturing processes can also involve removing material such as in polymers that are microstructured using photolithographic techniques [6]. The latter manufacturing process uses a masking pattern with a high-resolution microstructure attached to the substrate surface before chemical etching $[7,8]$. Etching is also applicable to glass substrates [9]; however, material removal might be more cost-effective and time-efficient with a mechanical process. Furthermore, influence of side-etching should be considered to obtain a high-resolution microstructure. Current mechanical structuring processes for engineering glass surfaces lack sufficient detail at the microscale [10] owing to the brittleness of glass.

Therefore, in this research, an abrasive slurry-jet [11], more specifically a microslurry-jet (MSJ) [12], was used for microstructuring of glass surfaces. The MSJ process is a wet blasting process, where a water jet comprising small and hard particles with micrometre dimensions (slurry) was sprayed onto the substrates. Earlier studies have shown that applying the MSJ method could structure engineering surfaces (surfaces made of alloys, plastics, glass, and ceramics) to the order of nanometers in the vertical direction without the occurrence of microscopic cracks and microstructural defects on these surfaces $[13,14]$. Moving the MSJ nozzle during the machining process can provide continuously curved surface textures; however, the surface structures in the horizontal direction depend on the size of the nozzle, causing limitations in the machining resolution [15]. Hence, to compensate for this limitation, the combined application of a conventional photoresist masking process and the MSJ mechanical removal process was considered [16,17].

The aim of the current study was to research and assess the feasibility of using this combined masking and MSJ process for mircostructuring glass surfaces in terms of the machining accuracy and changes in the hydrophobic/hydrophilic characteristics of the machined surfaces.

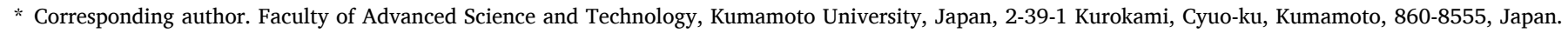

E-mail address: y-naka@mech.kumamoto-u.ac.jp (Y. Nakanishi).
} 


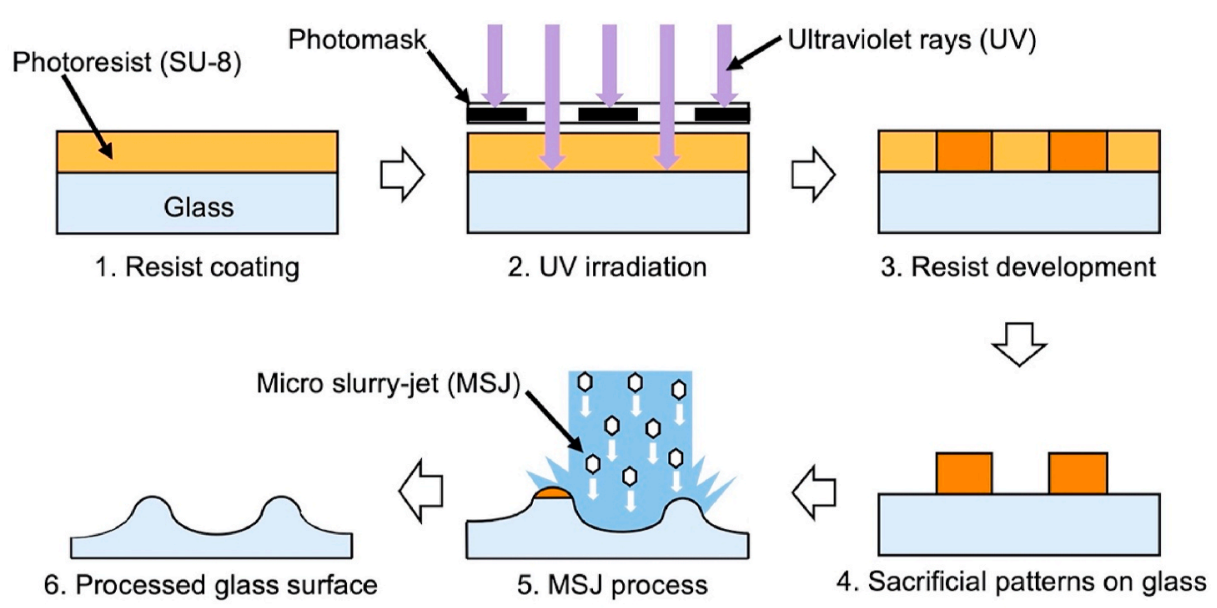

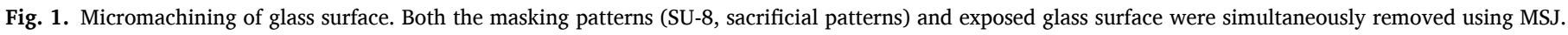

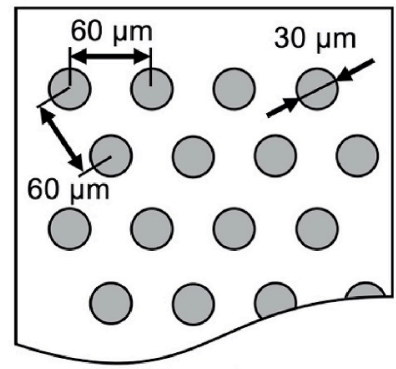

Type-A

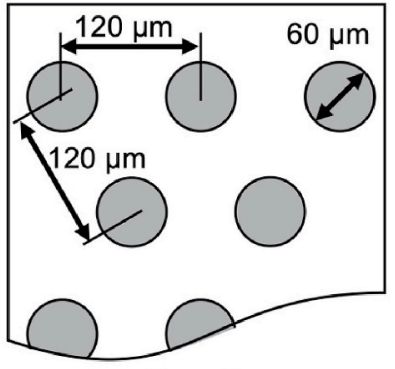

Type-B

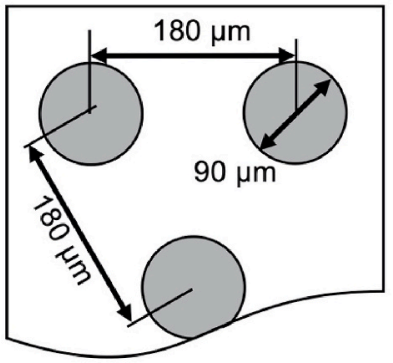

Type-C

Fig. 2. Design of the photomasks.

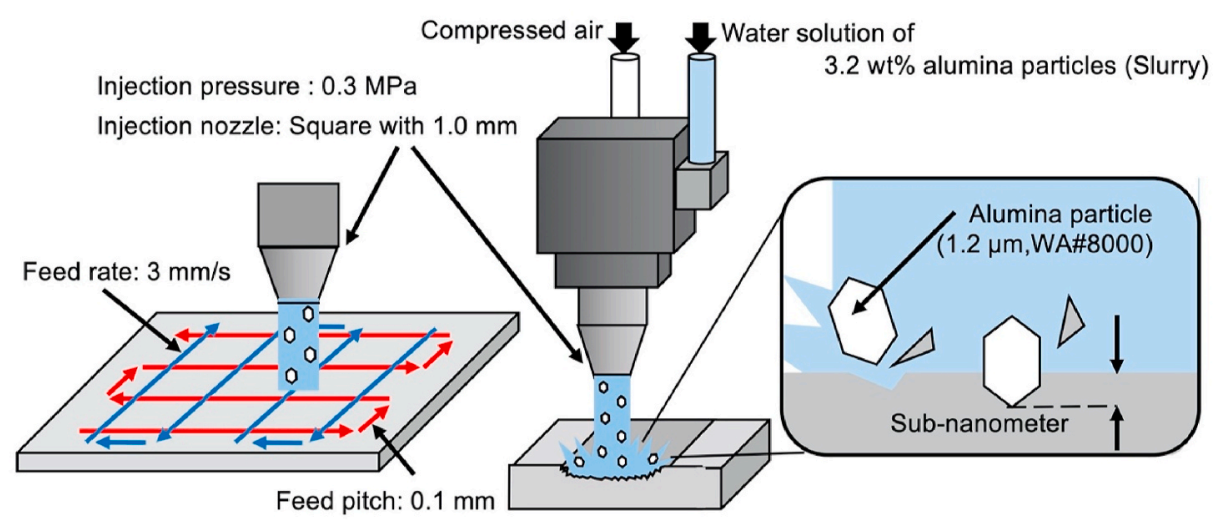

Fig. 3. MSJ processing and movements of the injection nozzle.

\section{Materials and methods}

\subsection{Micromachining of glass surface by combined masking and MSJ process}

Fig. 1 illustrates the micromachining process. Flat glass composed of $\mathrm{SiO}_{2}$ with $13 \% \mathrm{Na}_{2} \mathrm{O}$ and $10 \% \mathrm{CaO}$ was the material used for processing; it was ultrasonically cleaned using methanol, acetone, and ultrapure water. The organic compounds and other contaminants on the glass surface were also removed using piranha solution (a 3:1 mixture of sulfuric acid and $30 \%$ hydrogen peroxide, and up to $40 \%$ hydrogen fluoride) $[18,19]$.

In the resist coating process, SU-8 3050, a photocurable epoxy resin
(KAYAKU MICROCHEM, Japan), was used as the photoresist [20,21]. The glass was soaked in a silane coupling agent (KBM-403, ShinEtsu, Japan) for $5 \mathrm{~min}$ to increase the bonding strength between glass (inorganic material) and SU-8 (organic material). The silane coupling agent contains two or more different reactive groups. One reactive group is capable of chemically bonding with an inorganic material, and the other is capable of chemically bonding with an organic material [22]. The SU-8 was coated on the glass surface, where three target thicknesses (15, 30 , and $60 \mu \mathrm{m}$ ) were adjusted by using a spin coating technology. The coated SU-8 was undergone for the residual stress relaxation for $12 \mathrm{~h}$ at room temperature of $20-25{ }^{\circ} \mathrm{C}$.

In the ultraviolet (UV) irradiation and resist development processes, SU-8 was irradiated by UV rays passing through the photomask; the 

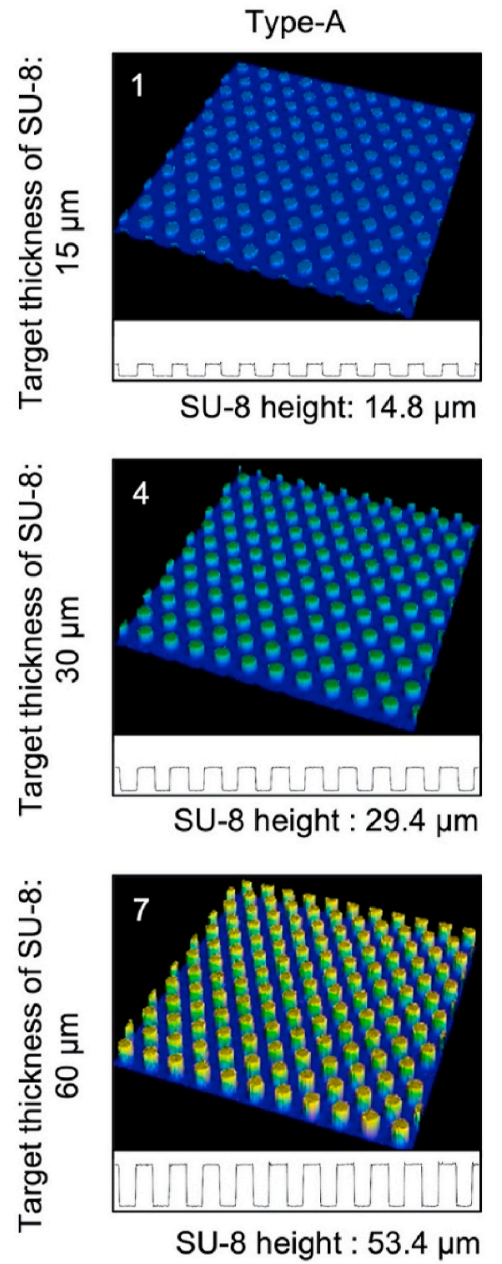
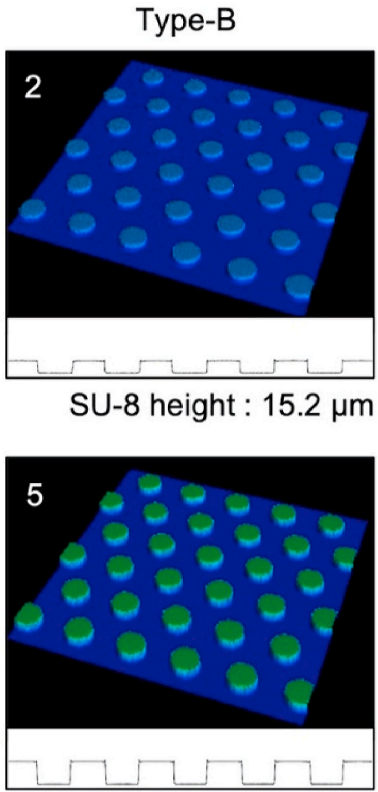

SU-8 height : $29.0 \mu \mathrm{m}$

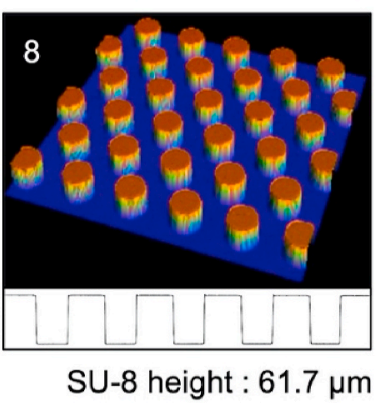

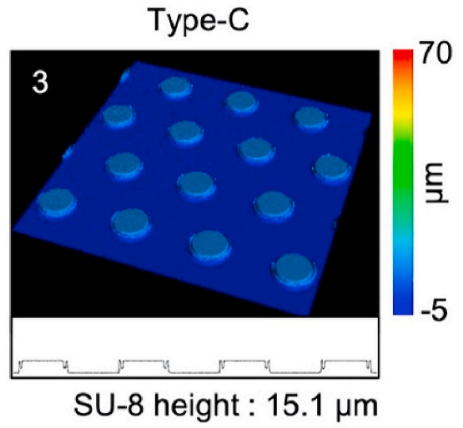

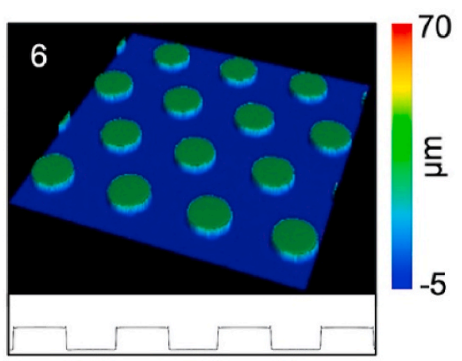

SU-8 height : $28.2 \mu \mathrm{m}$

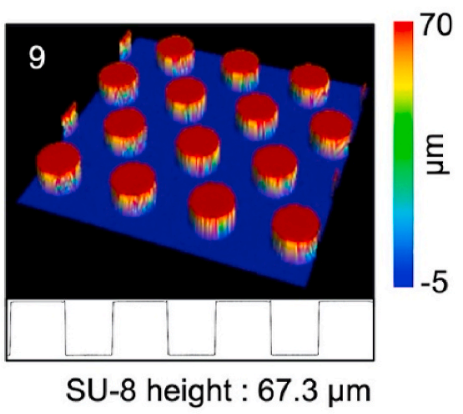

Fig. 4. Confocal laser microscopy images of glass surfaces after the masking processes.

irradiated parts were cured and retained on the glass. The design of the photomasks is illustrated in Fig. 2. Three patterns were prepared, i.e., Type-A (diameter: $30 \mu \mathrm{m}$, pitch: $60 \mu \mathrm{m}$ ), Type-B (diameter: $60 \mu \mathrm{m}$, pitch: $120 \mu \mathrm{m}$ ), and Type-C (diameter: $90 \mu \mathrm{m}$, pitch: $180 \mu \mathrm{m}$ ). The pattern pitch was twice the diameter of each pattern, while the illumination intensity of UV rays was $18.7 \mathrm{mw} / \mathrm{cm}^{2}$. The light quantity for each target thickness of SU-8 $(15,30$, and $60 \mu \mathrm{m})$ was adjusted by the exposure time; $336.6 \mathrm{~mJ} / \mathrm{cm}^{2}$ for $15 \mu \mathrm{m}\left(=18.7 \mathrm{mw} / \mathrm{cm}^{2} \times 18 \mathrm{~s}\right), 467.5 \mathrm{~mJ} / \mathrm{cm}^{2}$ for 30 $\mu \mathrm{m}\left(=18.7 \mathrm{mw} / \mathrm{cm}^{2} \times 25 \mathrm{~s}\right)$, and $748.0 \mathrm{~mJ} / \mathrm{cm}^{2}$ for $60 \mu \mathrm{m}(=18.7 \mathrm{mw} /$ $\mathrm{cm}^{2} \times 40 \mathrm{~s}$ ). The non-irradiated parts were removed through immersion in 2-acetoxy-1-methoxypropane, and thus SU-8 patterns were created on the glass surface.

In the MSJ process, both the SU-8 patterns and exposed glass surface were simultaneously removed. Fig. 3 illustrates the MSJ process and movements of the nozzle during the process (MSE-T102K-5050, Palmeso, Japan). A slurry consisting of pure water with $3.2 \mathrm{wt} \%$ alumina particles was prepared. Micropolyhedral alumina particles were used, and their average diameter was $1.2 \mu \mathrm{m}$ (WA \# 8000). The slurry was sprayed vertically on the glass surfaces through an injection nozzle with a square-shaped cross-section of $1 \mathrm{~mm}$ width, using compressed air at $0.3 \mathrm{MPa}$. The injection nozzle could be moved parallel to the processed surface using a numerical control system. The maximum range of the processed area was $50 \mathrm{~mm} \times 50 \mathrm{~mm}$. The nozzle was moved to achieve a feed rate of $3 \mathrm{~mm} / \mathrm{s}$ and feed pitch of $0.1 \mathrm{~mm}$. After finishing a reciprocal movement on a surface, the movement direction of the nozzle was changed by $90^{\circ}$ to finish the next reciprocal movement on the surface. A sequence of the MSJ processing was continued until the sacrificial patterns of the SU- 8 were removed by the MSJ. The glass surface with microstructures was created without post-treatment, such as removal of the SU-8 patterns.

\subsection{Characterisation of processed glass}

The surfaces processed through the combined masking and MSJ process were analysed using a confocal laser microscope (LEXT OLS 4100 , Olympus, Japan). The shapes of the microstructures were evaluated numerically and by utilising imaging techniques. The contact angle of water was also measured using the droplet method (PCA-11, KYOWA, Japan) [27] because these types of microstructures are similar to those observed on lotus leaf surfaces [3,23,24]; these structures partially control surface characteristics, such changes in the hydrophobic/hydrophilic features [25,26]. Before performing the measurements, all machined glasses were cleaned in an ultrasonic cleaner using ethanol, acetone, and ultrapure water. 


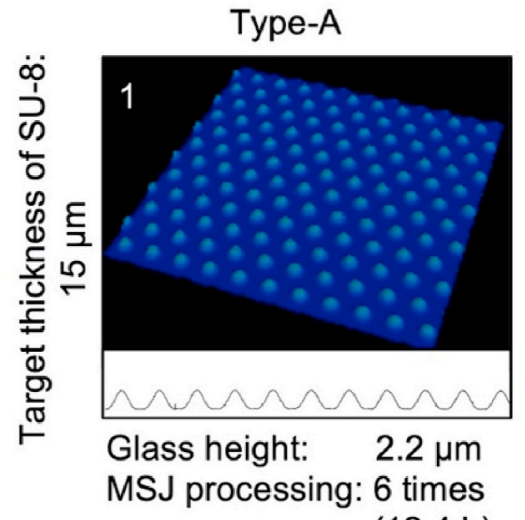

$(12.4 \mathrm{~h})$

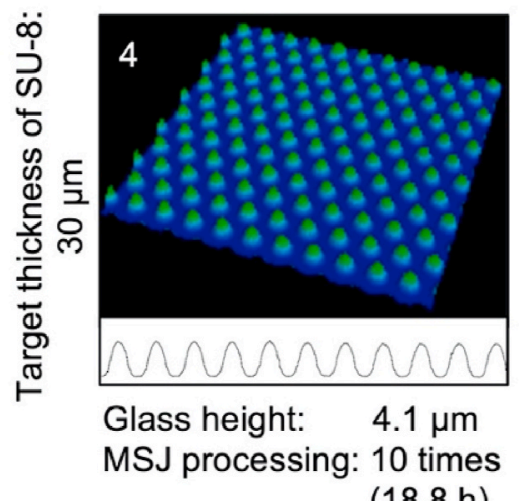

$(18.8 \mathrm{~h})$

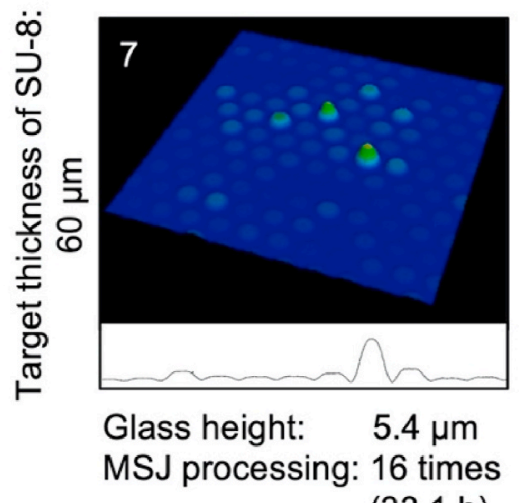

(33.1 h)
Type-B

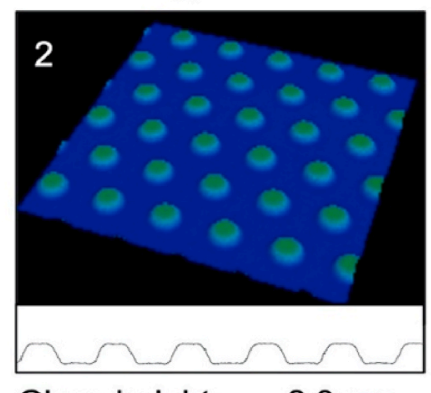

Glass height: $\quad 2.3 \mu \mathrm{m}$ MSJ processing: 8 times

(16.5 h)

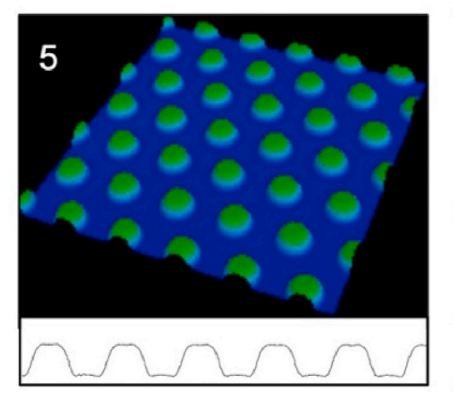

Glass height: $\quad 3.7 \mu \mathrm{m}$ MSJ processing: 10 times (19.1 h)

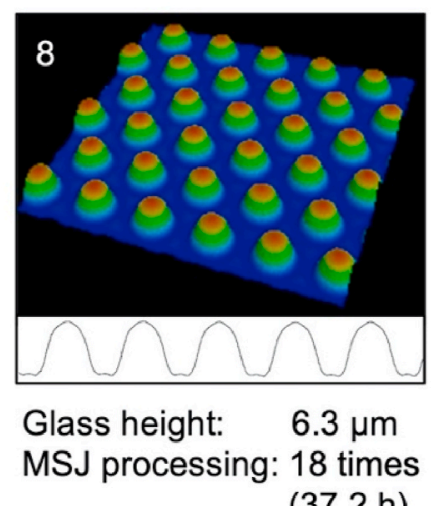

Type-C
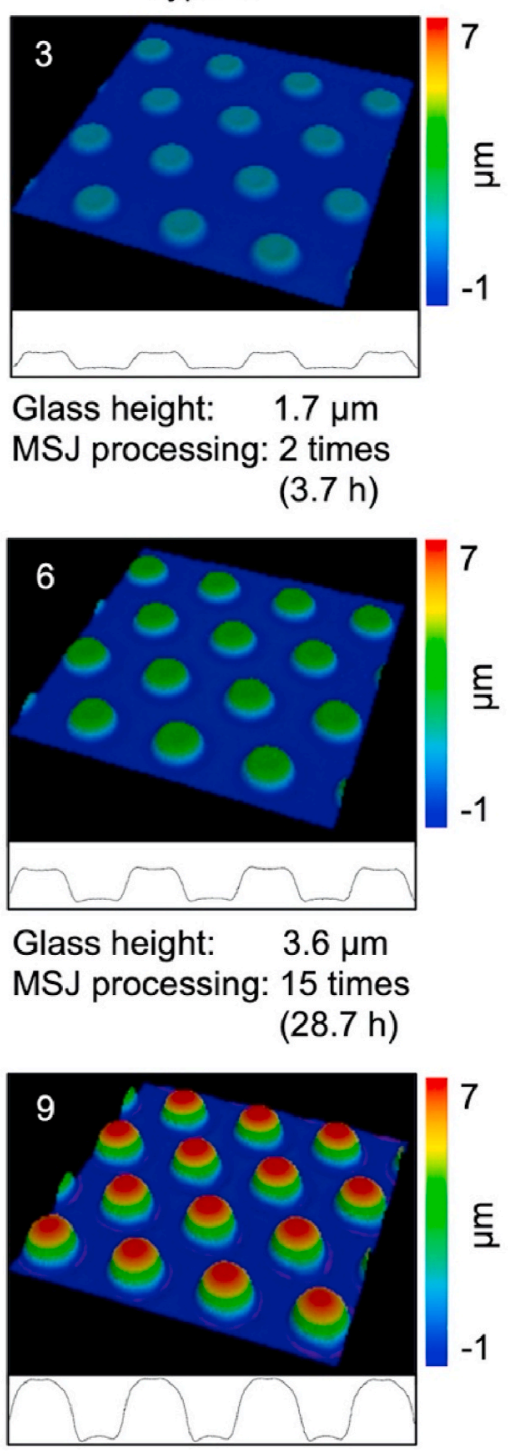

Glass height: $6.9 \mu \mathrm{m}$ MSJ processing: 16 times

$(33.1 \mathrm{~h})$

Fig. 5. Confocal laser microscopy images of the processed glass surfaces (after the MSJ process).

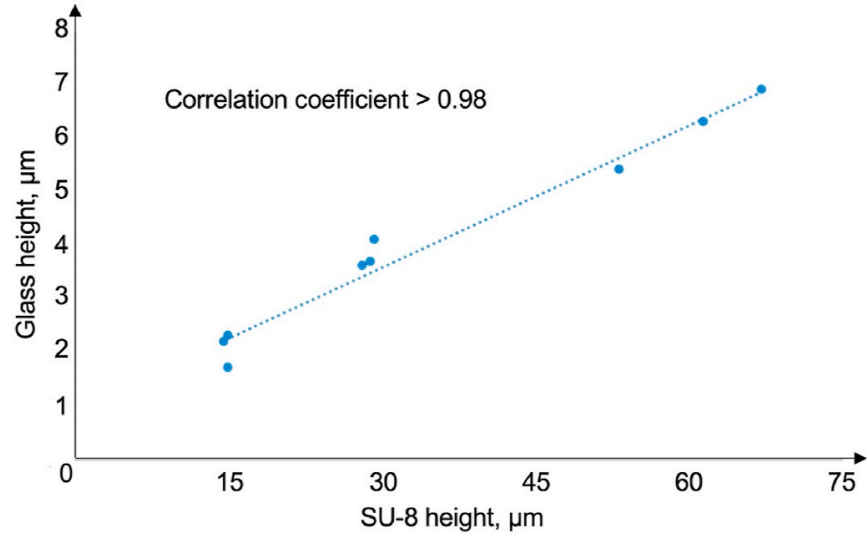

Fig. 6. Relationship between removal rates of SU-8 sacrificial patterns and exposed glass surface.

\section{Results and discussion}

Fig. 4 shows the glass surfaces after the masking processes, with the sacrificial patterns formed as indicated in Fig. 1(4) and Fig. 2. The photoresist was precisely patterned to obtain the Type-A, Type-B, and Type-C patterns shown in Fig. 2. Confocal laser microscopy analysis confirmed that the target heights of the sacrificial patterns, namely 15 , 30 , and $60 \mu \mathrm{m}$, were achieved.

Fig. 5 shows the processed glass surface after the MSJ process (see Fig. 1(6) for a schematic representation of this step). The results show

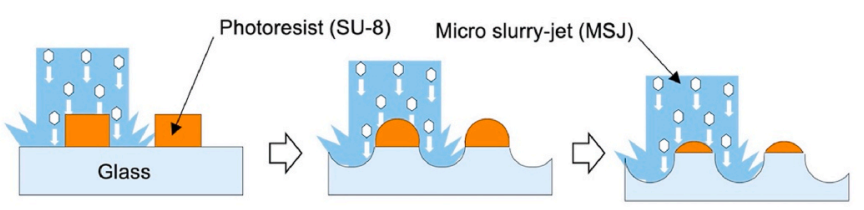

Fig. 7. MSJ processing characteristics. 

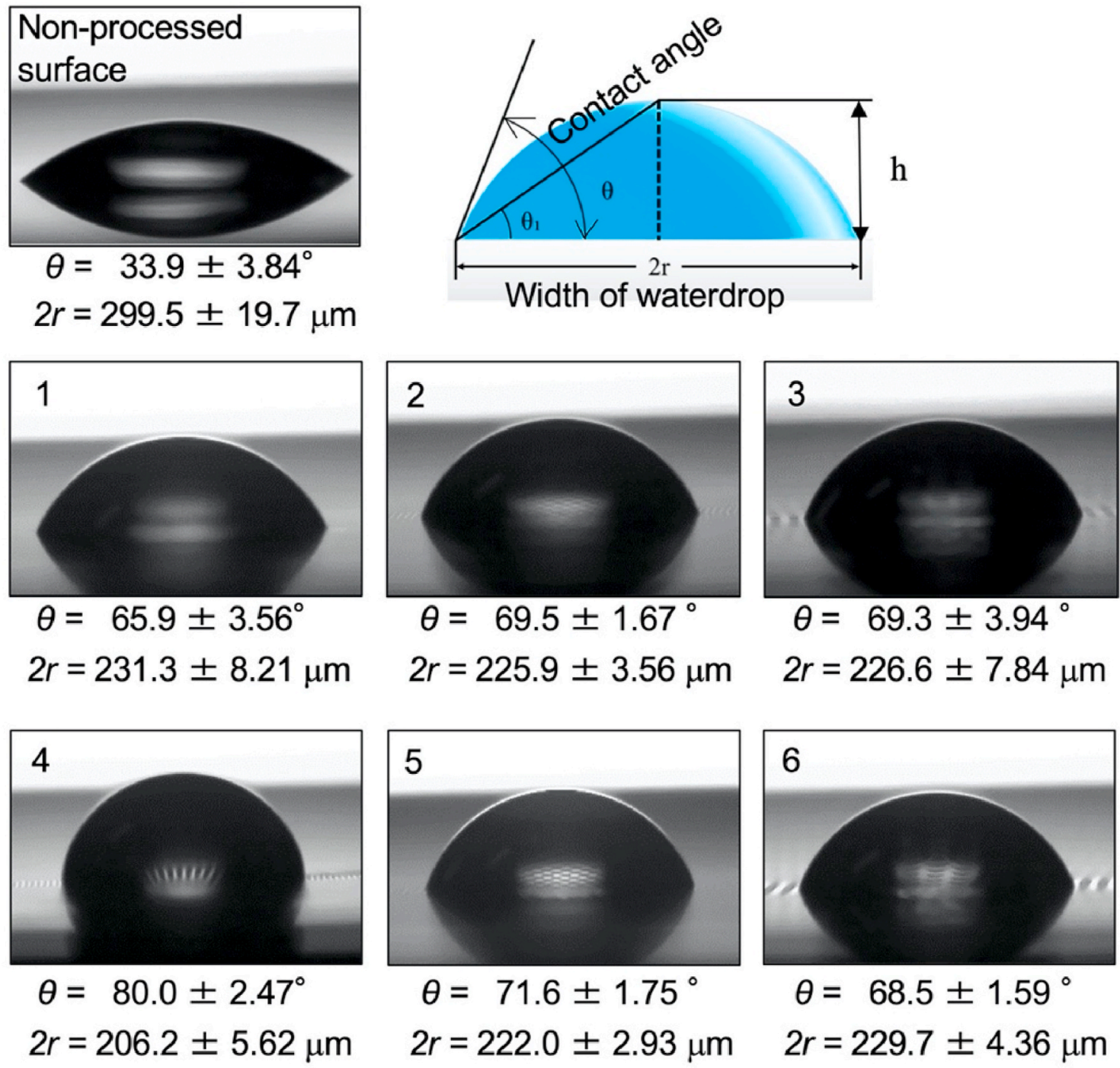

$\theta=71.6 \pm 1.75^{\circ}$
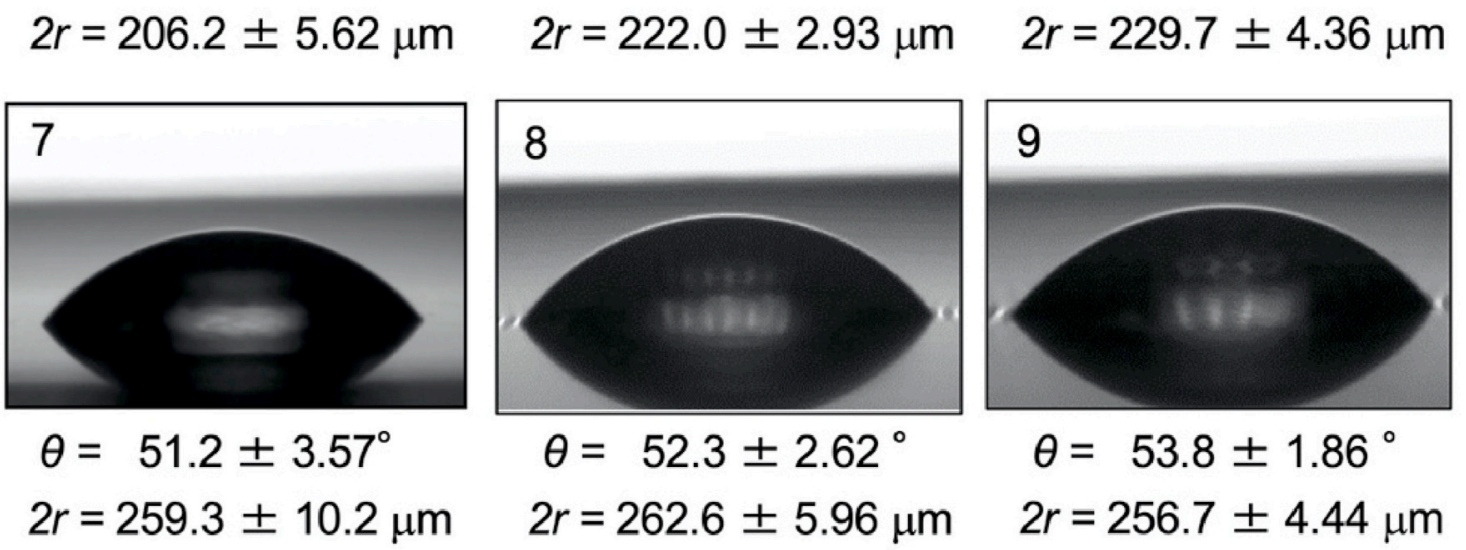

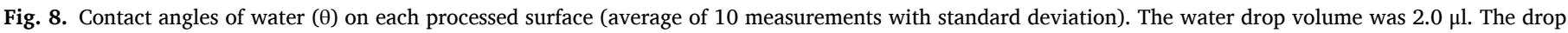
diameters $(2 r)$ were also measured.

the formation of continuously curved convex microstructures with a highly transparent glass surface. The MSJ processes shown in Fig. 3 were repeated and terminated at the point where the sacrificial patterns of the SU-8 were removed by visual inspections. The number of MSJ processes was related to the height of the SU-8. The higher the SU- 8 was, the longer the processing time of MSJ was. The heights of the convex structures created depend on the difference between the removal rates of SU-8 and glass (see Fig. 6). The removal ratio of glass to SU-8 by the MSJ process was estimated to be 0.0884 . This indicates that the SU- 8 was more easily removed by the MSJ process compared with glass. Higher wear resistance values of masking materials should be explored when higher convex structures are requested. A structure with sharp-edge was processed to a curved surface shape by the MSJ process (Fig. 7). Therefore, the Type-A pattern with a smaller diameter became conical, and the Type-C pattern with a larger diameter had a trapezoidal shape. A missing pattern was observed when the smallest diameter and the highest SU-8 sacrificial patterns were obtained (Fig. 4(7)) after the MSJ process (Fig. 5(7)). As Type-A had a small pattern diameter, the adhesion between the glass surface and SU-8 was low. Therefore, during the MSJ processes, SU-8 separated from the glass surface at certain 
locations. In this study, SU-8 was tested as the masking resin. Micropatterns with higher resolution can be created by exploring different materials for forming sacrificial patterns, their compatibility with glass, and their wear resistance in slurry erosion.

Fig. 8 shows the contact angle of water on the glass surfaces. From the measurements, it is clear that the processed glass surface becomes less hydrophilic owing to microstructuring; this is because the contact angle increased from approximately $34^{\circ}$ to a maximum of approximately $80^{\circ}$. However, hydrophilic mechanisms underlying the surface structure were not discussed because the size of convex structures was relatively large compared to the diameter of water droplets. Changing glass surfaces from hydrophilic to hydrophobic might likely involve an optimised design of the micropatterns, especially with respect to the hierarchical structuring of the glass surface $[23,28]$.

\section{Conclusions}

The combined application of the photoresist masking and MSJ mechanical removal processes for creating microstructures can be directly applied for processing numerous engineering materials to create structured surfaces. The results of this work showed that this process can be applied successfully to glass. The resulting convex microstructural features up to $30 \mu \mathrm{m}$ in diameter and $4 \mu \mathrm{m}$ in height are beneficial in enhancing the hydrophobicity of glass surfaces. Post-treatment, such as removal of the SU-8 patterns, was not required. By exploring materials for forming masking patterns, their compatibility with glass, and their wear resistance, micropatterns with higher resolution can be achieved in future; thus, this method is promising and feasible for producing structured engineering surfaces.

\section{Declaration of competing interest}

The authors declare that they have no known competing financial interests or personal relationships that could have appeared to influence the work reported in this paper.

\section{Acknowledgements}

This work was supported by JSPS KAKENHI Grant Number 19KK0096, the Environment Research and Technology Development Fund (1-1908) of the Environmental Restoration and Conservation Agency of Japan, and the Interdisciplinary Research Project of the Institute of Industrial Nanomaterials (IINa), Kumamoto University.

\section{References}

[1] Bijani D, Deladi EL, De Rooij MB, Schipper DJ. The influence of surface texturing on the frictional behaviour in starved lubricated parallel sliding contacts. Lubricants 2019;7:68. https://doi.org/10.3390/lubricants7080068.

[2] Sergachev DA, Matthews DTA, Van der Heide E. An empirical approach for the determination of skin elasticity: finger pad friction against textured surfaces. Biotribology 2019;18:100097. https://doi.org/10.1016/j.biotri.2019.100097.

[3] Zhang M, Feng S, Wang L, Zheng Y. Lotus effect in wetting and self-cleaning. Biotribology 2016;5:31-43. https://doi.org/10.1016/j.biotri.2015.08.002.

[4] Van Kuilenburg J, Masen MA, Van der Heide E. A review of fingerpad contact mechanics and friction and how this affects tactile perception. Proc Inst Mech Eng Part J: J Eng Tribol 2015;229:243-58. https://doi.org/10.1177/ 1350650113504908.

[5] Al-Milaji KN, Zhao H. Fabrication of superoleophobic surfaces by mask-assisted electrospray. Appl Surf Sci 2017;396:955-64. https://doi.org/10.1016/j. apsusc.2016.11.067.
[6] Ginestra PS, Madou M, Ceretti E. Production of carbonized micro-patterns by photolithography and pyrolysis. Precis Eng 2019;55:137-43. https://doi.org/ 10.1016/j.precisioneng.2018.08.019.

[7] Xi Y, Zhang W, Fan Z, Ma Q, Wang S, Ma D, Jiang Z, Li H, Zhang Y. A facile synthesis of silicon nanowires/micropillars structure using lithography and metalassisted chemical etching method. J Solid State Chem 2018;258:181-90. https:// doi.org/10.1016/j.jssc.2017.07.034.

[8] Jheng Y-S, Lee Y-C. Fabrication of micro/nano hierarchical structures with analysis on the surface mechanics. Appl Surf Sci 2016;384:393-9. https://doi.org/10.1016/ j.apsusc.2016.05.048.

[9] Saito Y, Okamoto S, Miki A, Inomata H, Hidaka T, Kasai H. Fabrication of microstructure on glass surface using micro-indentation and wet etching process. Appl Surf Sci 2008;254:7243-9. https://doi.org/10.1016/j.apsusc.2008.05.320.

[10] Matsumura T, Kakishita M. Parametric glass milling with simultaneous control. J Manuf Process 2013;15:1-7. https://doi.org/10.1016/j.jmapro.2012.09.009.

[11] Nouraei H, Wodoslawsky A, Papini M, Spelt JK. Characteristics of abrasive slurry jet micro-machining: a comparison with abrasive air jet micro-machining. J Mater ProcessTechnol 2013;213:1711-24. https://doi.org/10.1016/j. jmatprotec.2013.03.024.

[12] Iwai Y, Mstsubara T, Hirai Y, Hogmark S. Development of a new type micro slurryjet erosion (MSE) tester for evaluation of wear properties of hard thin coatings. Lubric Sci 2009;21:213-26. https://doi.org/10.1002/ls.81.

[13] Baba T, Nakashima Y, Takahashi S, Matsubara T, Yin L, Nakanishi Y. Micro slurryjet for surface processing of dental ceramics. Biosurf. Biotribol. 2019;5:8-12. https://doi.org/10.1049/bsbt.2018.0028.

[14] Yin L, Baba T, Nakanishi Y. Fracture-free surfaces of CAD/CAM lithium metasilicate glass-ceramic using micro-slurry jet erosion. J. Mech. Behav. Biomed. Mater. 2018;80:59-67. https://doi.org/10.1016/j.jmbbm.2018.01.022.

[15] Nakanishi Y, Nakashima Y, Fujiwara Y, Komohara Y, Takeya M, Miura H, Higaki H. Influence of surface profile of Co-28Cr-6Mo alloy on wear behaviour of ultrahigh molecular weight polyethylene used in artificial joint. Tribol Int 2018;118:538-46. https://doi.org/10.1016/j.triboint.2017.06.030.

[16] Shibata K, Nakashima Y, Nakanishi Y. Anti-fingerprint glass surface created by mechanical removal process. J Biomech Sci Eng 2019;14. https://doi.org/ 10.1299/jbse.19-00388. 19-00388.

[17] Nakanishi Y, Baba T, Moriyama T, Nakashima Y. Surface micromachining by micro slurry-jet. J. Biomech. Soc. 2017;41:109-14. https://doi.org/10.3951/sobim.41.3_ 109.

[18] Feitosa SA, Lima NB, Yoshito WK, Campos F, Bottino MA, Valandro LF, Bottino MC. Bonding strategies to full-contour zirconia: zirconia pretreatment with piranha solution, glaze and airborne-particle abrasion. Int J Adhesion Adhes 2017;77: 151-6. https://doi.org/10.1016/j.ijadhadh.2017.05.007.

[19] Hussain M, Nakahira A, Nishijima S, Niihara K. Effects of coupling agents on the mechanical properties improvement of the $\mathrm{TiO}_{2}$ reinforced epoxy system. Mater Lett 1996;26:299-303. https://doi.org/10.1016/0167-577X(95)00253-7.

[20] Psoma SD, Van der Wal PD, Frey O, De Rooij NF, Turner AP. A novel enzyme entrapment in SU-8 microfabricated films for glucose micro-biosensors. Biosens Bioelectron 2010;26:1582-7. https://doi.org/10.1016/j.bios.2010.07.117.

[21] Saha AA, Mitra SK, Tweedie M, Roy S, McLaughlin J. Experimental and numerical investigation of capillary flow in SU8 and PDMS microchannels with integrated pillars. Microfluid Nanofluidics 2009;7:451-5. https://doi.org/10.1007/s10404008-0395-0.

[22] Zhang J, Tan KL, Gong HQ. Characterization of the polymerization of SU-8 photoresist and its applications in micro-electro-mechanical systems (MEMS). Polym Test 2001;20:693-701. https://doi.org/10.1016/S0142-9418(01)00005-8.

[23] Gao L, McCarthy TJ. The "Lotus Effect" explained: two reasons why two length scales of topography are important. Langmuir 2006;22:2966-7. https://doi.org/ 10.1021/la0532149.

[24] Marmur A. The lotus effect: superhydrophobicity and metastability. Langmuir 2004;20:3517-9. https://doi.org/10.1021/la036369u.

[25] Tokuhisa H, Tsukamoto S, Morita S, Ise S, Tomita M, Shirakawa N. Fabrication of micro-textured surfaces for a high hydrophobicity by evaporative patterning using screen mesh templates. Appl Surf Sci 2017;400:64-70. https://doi.org/10.1016/j. apsusc. 2016.11.213.

[26] Abraha Marmur x-. The Lotus effect: superhydrophobicity and metastability. Langmuir 2004;20:3517-9.

[27] Kwok DY, Gietzelt T, Grundke K, Jacobasch H-J, Neumann AW. Contact angle measurement and contact angle interpretation. 1. Contact angle measurements by axisymmetric drop shape analysis and a goniometer sessile drop technique. Langmuir 1997;13:2880-94. https://doi.org/10.1021/la9608021.

[28] Moronuki N, Takayama A, Kaneko A. Design of surface texture for the control of wettability. Trans Jpn Soc Mech Eng B 2004;70(693):1244-9. https://doi.org/ 10.1299/kikaib.70.1244 [in Japanese]. 